\title{
The Impact of Higher Fixed Pay and Lower Bonuses on Productivity
}

\author{
Maurice J. G. Bun ${ }^{1}$ • Leo C. E. Huberts ${ }^{1}$
}

Published online: 17 January 2018

(C) The Author(s) 2018. This article is an open access publication

\begin{abstract}
This study analyzes the effects of performance related pay on productivity exploiting a change in the payment structure of a large Dutch marketing company. Specifically, we investigate the consequences for company sales of higher fixed pay in combination with lower bonuses. Exploiting shift level data of individual workers we find that average productivity decreases when the pay structure shifts more to fixed pay. Further analysis shows that this drop in productivity is larger for older workers and for high-ability employees, while over time the negative effect of the new system becomes smaller.
\end{abstract}

Keywords Bonuses $\cdot$ Fixed pay $\cdot$ Performance pay $\cdot$ Piece rate $\cdot$ Productivity

JEL Classification J00 $\cdot$ J31 $\cdot$ J33

\section{Introduction}

As the output of companies depends largely on the productivity of its workers, it is important to motivate employees to achieve maximum performance. Including performance pay in compensation systems is one of the instruments used to provide workers with incentives to maximize their productivity. Performance pay is the opposite of fixed pay, as it depends on the variable performance of the worker. Performance related pay, i.e. piece rates and bonuses, is typically beneficial for productivity for two reasons (Lazear 2000). First, performance related pay can be used to increase

Maurice J. G. Bun

m.j.g.bun@uva.nl

1 Faculty of Economics and Business, University of Amsterdam, Amsterdam, Netherlands 
the effort of workers. Second, it may induce a sorting effect in the sense that it attracts new workers with relatively high ability.

There is a large empirical literature on the incentives associated with different pay structures, i.e. how firms design pay structures to induce employees to maximize performance. ${ }^{1}$ Empirical research is often based on personnel data from a single firm. Examples are Lazear (2000) and Bandiera et al. (2005) on the impact of introducing piece rates on productivity, Van Herpen et al. (2005) on the effects of performance measurement and piece rates on motivation and Kishore et al. (2013) on bonuses and commissions. ${ }^{2}$ Typically the empirical evidence is in favor of performance related pay. ${ }^{3}$

In this study we analyze personnel data provided by a large field marketing company based in the Netherlands. The company offers retailers, publishers and charities a sales and fundraising channel. Although the company operates in four different markets in Europe, the data used for analysis in this paper were collected during their activities in the Netherlands only. The data cover all of 2013 and January through October of 2014.

We investigate how worker behavior and productivity depend on performance pay systems. As of the first of January 2014, the company changed its pay structure by introducing a higher fixed pay and lower variable pay. The variable part of the wage is divided into both piece rate pay and bonuses. Incentive pay in the form of piece rates is defined by payment on the basis of output (Lazear 1986). Bonuses are granted when a specific output number is reached, this can be both individually and as a team. As the fixed pay went up, piece rates stayed unchanged and bonuses went down.

The data of roughly 3000 unique employees in 2013 and 2200 in 2014 are available, with worker specific shift performance as the appropriate performance measure. This shift information will be analyzed using a range of models and estimation techniques, to identify the effects of the payment system change on workers' performance. In our empirical analysis we distinguish between average and heterogeneous productivity effects. Regarding the latter we investigate whether the response has been different across age, position and time.

The novel aspect of the analyzed pay structure change is that it implies a shift away from variable pay toward higher fixed pay. The introduction of performance pay has been analyzed extensively in the literature, but empirical evidence on the impact of the (partial) abolition of performance pay on productivity is scarce. Recent studies (Gittleman and Pierce 2013; Forth et al. 2014) indicate a decline in the share of jobs with performance related pay. In light of this shift toward more fixed pay and less variable pay, our empirical analysis provides a first case study of the potential productivity effects.

The rest of this paper is organized as follows. "Research Design" will describe in detail the research design, in particular the various compensation systems covered in this study. In "Theoretical Background and Predictions" relevant literature will be

\footnotetext{
${ }^{1}$ See Prendergast (1999) for a review of theoretical literature on incentive pay.

${ }^{2}$ Some examples of studies using firm-level data are Origo (2009) on Italian firms and Gielen et al. (2010) on Dutch firms.

${ }^{3}$ See Jones et al. (2006) for more examples and a review of the various approaches.
} 
reviewed to provide a theoretical background of the incentives and choices within the different payment systems. "Average Effects" and "Heterogeneous Effects" report the results from the empirical analysis. "Concluding Remarks" concludes.

\section{Research Design}

In this Section we describe the compensation system of the Dutch marketing company and provide insight into the changes in monetary incentives for employees. The company employs three types of positions, i.e. talents, promoters and captains. A 'talent' is an employee that has worked less than 5 shifts, a 'promoter' is an employee that has worked at least 4 shifts and performed well enough to be offered a contract. A 'captain' is the leader of the shift team, which depending on the project consists of 2 to 4 workers.

Talents have to show progress in their shift performance in order to become promoter. Promoters have to present consistent sales scores and can be laid off by captains in case of underperformance. Promoters with good performance and leadership skills can be promoted to captain by the area managers. Promotions and dismissals are the responsibility of the captains together with the area managers.

Talent and promoter functions have identical pay. Captains, however, get a higher base salary as they are paid extra for organizational activities as team leader. Furthermore, in some cases a captain gets higher bonuses.

The main task of workers is sales and fundraising. The result of a shift can be summarized in a score, which is basically the sales count. The main sales projects of the company are selling newspaper subscriptions and acquiring charity donators. The pay structure of the company consists of fixed pay, piece rates and bonuses. Irrespective of the shift score the workers earn a fixed pay, which is determined by the number of hours worked and a hourly rate. Furthermore, for each sale the worker is on a piece rate, while at certain scores an additional bonus can be obtained. Bonuses can be earned individually or as a team.

As of the first of January 2014, the company changed its pay structure. Piece rates stayed unaltered, while fixed pay and bonuses did change. The reason for this change was to comply with minimum wage regulation, hence it was not directly related to worker productivity. The new pay structure was announced at the end of 2013. There were no other large organizational changes at the time, which ensures the identification of the impact of the new compensation system.

An overview of the old and new fixed pay is reported in Table 1. In the old compensation system there was no age differentiation in fixed pay. Clear from Table 1 is the age differentiation in fixed pay in the new system and the resulting differences across ages for all workers. As said, the main reason for the age differentiation was to comply with minimum wage regulation in the Netherlands, which is age specific. Fixed pay was increased for all age categories above 18, while it was slightly decreased for ages 17 and 18 (and 19 too for captains). Especially older workers benefit substantially from the new fixed pay. 
Table 1 Fixed pay per shift

\begin{tabular}{|c|c|c|c|c|}
\hline \multirow[b]{2}{*}{ age } & \multicolumn{2}{|c|}{ Promoters/Talents } & \multicolumn{2}{|c|}{ Captains } \\
\hline & old & new & old & new \\
\hline all & 23.40 & & 39.00 & \\
\hline 17 & & 19.58 & & 27.42 \\
\hline 18 & & 22.56 & & 31.59 \\
\hline 19 & & 26.03 & & 36.44 \\
\hline 20 & & 30.49 & & 42.69 \\
\hline 21 & & 35.95 & & 50.32 \\
\hline 22 & & 42.15 & & 59.01 \\
\hline 23 & & 49.58 & & 69.42 \\
\hline
\end{tabular}

All numbers are in euros

An overview of the change in the bonus structure for acquiring charity donators is given in Table 2. In the old system there were two bonus types, i.e. awarded individually and for the team as a whole. Team bonuses are awarded only when the team performs well as a whole, with average individual scores of 6 and 9 in the old system and 4, 6 and 10 in the new system. For brevity we do not report the bonus structure of other projects (e.g. newspaper subscriptions) for which bonus thresholds and magnitude differ somewhat.

In general, in the new system there is no more individual bonus and only team bonuses are awarded. This may change part of the dynamics of the incentives for the employees. For example, consider a situation in which an employee is faced with an underperforming team incapable of achieving the score required for a team bonus. It is obvious that in a situation like this, both a promoter/talent and captain will have less monetary incentive to achieve high sales scores in the new than in the old system because individual bonuses have been abolished.

Changes in fixed pay structure were different for 7 different age groups as of January 1, 2014. Additionally, individual bonuses were abolished, while changes in team bonuses were made position specific. Therefore, in the remaining of this section we analyze the consequences of the new payment structure in terms of monetary incentives in more detail for different ages and functions. We do so by creating figures, which plot the amount (in euros) that a worker of particular age and position can possibly earn in a particular shift as a function of the shift score. We use the information on fixed pay and bonus structure from Tables 1 and 2 to create the graphs. 4

\footnotetext{
${ }^{4}$ Piece rates vary across products (higher commissions for higher donations for example), but do not vary between the old and new compensation system. Therefore, for ease of exposition a fixed commission of 6 euros per sale is taken in all figures. This fits the purpose of this analysis, as only the differences between the old and new system are important.
} 
Table 2 Bonuses per shift

\begin{tabular}{|c|c|c|c|c|c|c|}
\hline \multirow[b]{2}{*}{ score } & \multicolumn{2}{|c|}{ individual } & \multicolumn{2}{|c|}{ team $\mathrm{P} / \mathrm{T}$} & \multicolumn{2}{|c|}{ team C } \\
\hline & old & new & old & new & old & new \\
\hline \multicolumn{7}{|l|}{1} \\
\hline \multicolumn{7}{|l|}{2} \\
\hline \multicolumn{7}{|l|}{3} \\
\hline 4 & & & & 15 & & 15 \\
\hline 5 & 17.5 & & & & & \\
\hline 6 & & & 15 & 30 & 25 & 30 \\
\hline 7 & 27.5 & & & & & \\
\hline \multicolumn{7}{|l|}{8} \\
\hline 9 & 37.5 & & 30 & & 50 & \\
\hline 10 & & & & 45 & & 45 \\
\hline 11 & 47.5 & & & & & \\
\hline \multicolumn{7}{|l|}{12} \\
\hline 13 & 57.5 & & & & & \\
\hline \multicolumn{7}{|l|}{14} \\
\hline 15 & 67.5 & & & & & \\
\hline
\end{tabular}

Bonuses are in euros. $\mathrm{P} / \mathrm{T}$ is Promoters/Talents, while $\mathrm{C}$ is Captains. Score is shift score

\section{Promoters and Talents}

We analyze the youngest (17) and oldest (23) worker categories in more detail in Fig. 1. The payment structure for both ages from before the change in January 2014 is given by the dashed lines, while the solid lines reflect the new pay structure. Clearly visible is the change in fixed pay, which is the euro amount for a score equal to 0 . While this has slightly decreased for workers aged 17 , it more than doubled for workers aged 23 (see also Table 1). All lines are upward sloping reflecting the piece rate, while the kinks in the graphs represent the bonuses. Regarding the latter, visible are the differences in bonuses, both in magnitude and for different scores (see Table 2).

If we look at the promoters and talents aged 17 in Fig. 1, we observe that compensation is quite close in the new and old systems up to a sales score of 5. Above 5 , the old system awarded higher compensation for all scores. This provides promotors/talents aged 17 with less financial incentive to achieve higher scores in the new system.

In contrast, we observe a different pattern if we look at the new and old compensation curves for promoters and talents aged 23. In the new system the fixed pay is substantially higher and the financial incentive to achieve higher sales scores much lower. Especially up to a score of about 9 sales the new system is more rewarding than the old system and promoters/talents can earn the same wage with lower sales 

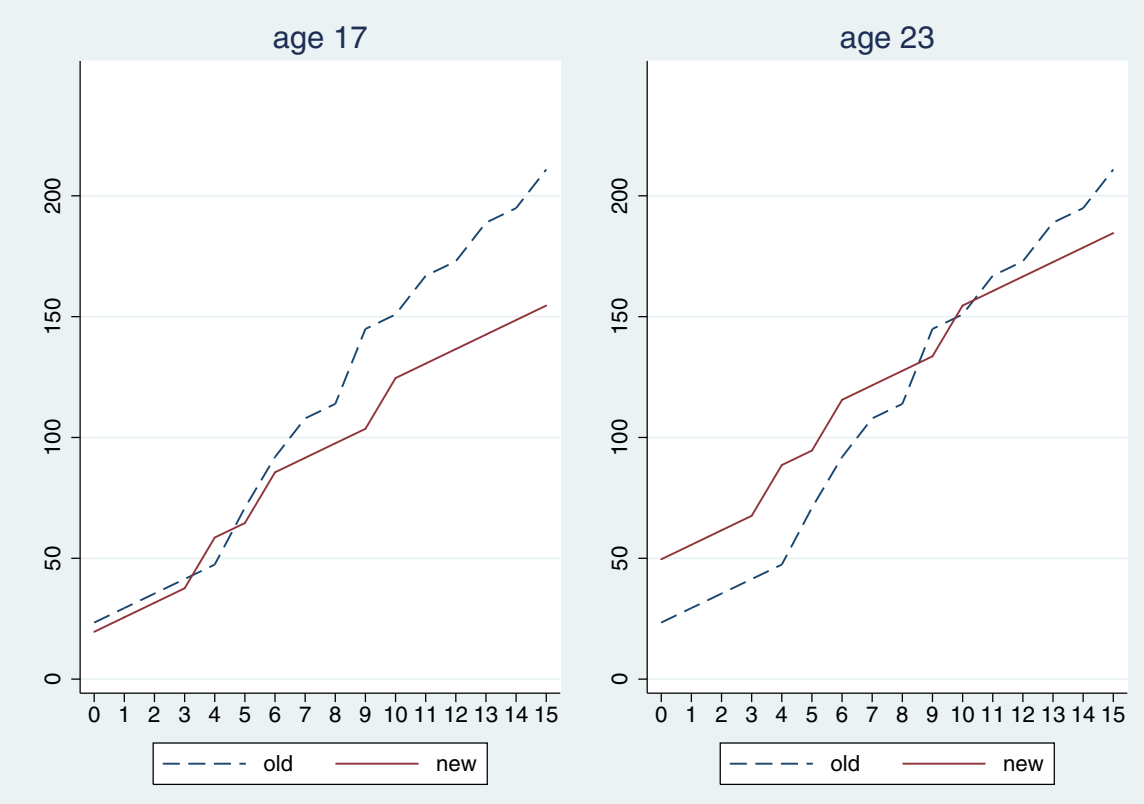

Fig. 1 Old and new compensation structures for Promoters/Talents. Vertical axis is compensation in euros, while horizontal axis is the number of sales

scores. A 50 euro payout, for example, is achieved by zero sales in the new system while in the old system the employee had to sell at least 4 units.

Both fixed pay and bonuses are different in the old and new compensation systems, while piece rates are unchanged. For ease of comparison, we fit a linear trend through the performance related pay, i.e. piece rate and bonus, for the new and old compensation systems. Note that this linear trend is the same for all age groups in the new system. The slope coefficient can be interpreted as the average variable pay. Variable pay in the old system is on average 13.58 euros per unit, while for the new system it is 9.70 euros only. This shows that the increase in compensation of extra output for promoters and talents was larger in the original compensation structure than in the new structure introduced in 2014. It therefore implies a smaller monetary incentive from performance related pay in the newer system.

Comparing the two graphs in Fig. 1, the direction of the effects of the change will be the same for all ages. However, their magnitude will most likely differ across age groups because the absolute changes in wages are pretty different. This justifies an empirical analysis of the change in compensation system for different age groups, as we shall see.

\section{Captains}

The representation of the two compensation systems for captains is shown in Fig. 2. 

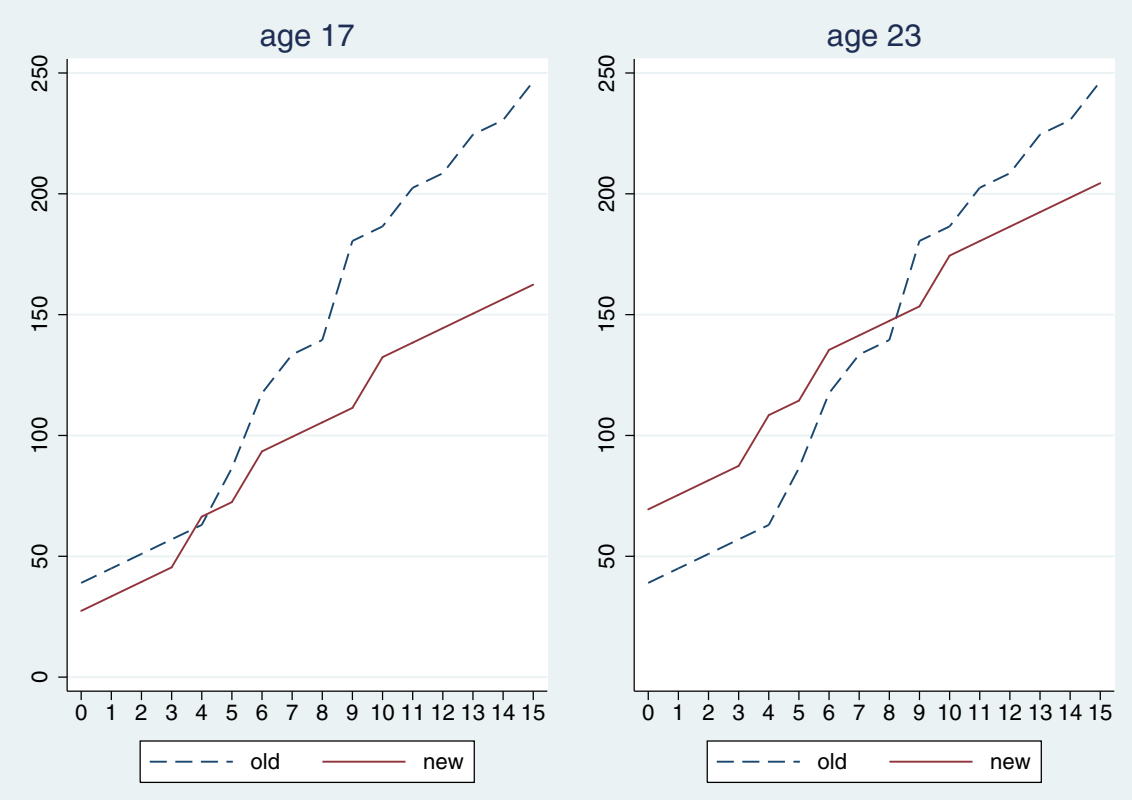

Fig. 2 Old and new compensation structures for Captains. See Fig. 1

For 17 year old workers the results are somewhat different to the results for the promoter/talent employees, i.e. for younger captains the old system produces higher compensation than the new system for all scores. For older workers the results are more or less the same compared to promoters/talents. Age 23 or higher receives more compensation in the new system for scores under 9, while the old system is more beneficial for higher scores.

The average variable pay is also for captains less in the new system than in the system before 2014. This indicates a smaller monetary incentive to perform for captains in the new system analogous with the promoter/talent results. The difference in average variable pay is even larger compared to promoters/talents (15.39 versus 9.70 euros), which suggests an even more negative change in monetary incentive for captains compared to promoters/talents in the new system.

\section{Theoretical Background and Predictions}

Agency theory offers an economic approach to human motivation and performance. It is the leading perspective used in economics to support financial incentives in order to motivate or increase performance (Young et al. 2012). Agency theory predicts that performance related pay, i.e. piece rates and bonuses, is beneficial for productivity for two reasons (Lazear 2000). First, performance related pay can be used to increase 
the effort of workers. Second, it may induce a sorting effect in the sense that it attracts new workers with relatively high ability.

Empirical evidence is often based on personnel data from a single firm. Lazear (2000) analyzes the impact on productivity of introducing piece rates within Safelite Corp. Bandiera et al. (2005) analyze the introduction of piece rates within a fruit picking farm in the UK. Van Herpen et al. (2005) analyze the effects of performance measurement and piece rates on motivation within a Dutch company. Jones et al. (2010) analyze the introduction of performance pay and teams in a Finnish food-processing plant. Kishore et al. (2013) analyze the switch from bonuses to commissions in a pharmaceutical firm. Typically the empirical evidence is in favor of the introduced performance related pay. For example, Lazear (2000) analyzes the effects on worker's productivity of an auto glass company's transition from a full fixed pay structure to a full piece rate system. He found a dramatic increase in performance, with average output per worker increasing by 44 percent.

From the analysis of the company's compensation systems it is clear that for all employees the monetary incentive to perform higher is lower in the compensation system implemented in January 2014 compared to the system in 2013. Since the changes in fixed pay and bonuses have been implemented simultaneously, in our empirical analysis we can only identify their joint effect on productivity. We expect that the agency theory applies here for several reasons. First, in the old compensation system workers have been subject to performance related pay already. Because workers are already used to piece rates and bonuses, it is expected that their intrinsic motivation will not change much in the new system. Second, as discussed before the changes in the system are large enough to expect a significant change in extrinsic motivation and therefore effort.

Based on agency theory we therefore expect the following effects (see e.g. Lazear, 2000). First, average scores will not increase in the new system, as the average return on added performance is less in the new than in the old compensation system. Second, the variance in output will decrease. If we assume that a worker will choose to invest less effort if it can produce the same utility; older workers in the new system will likely be able to achieve higher levels of utilities with less effort, and younger workers will be able to achieve the same utility with the same effort at lower score levels, and only a lower level of utility at the higher levels. Third, average age will not decrease. As average pay at any score for higher aged individuals rises with the new system, a decrease in average age would be counter intuitive and could point toward unobserved influences. Fourth, the change in compensation system may also affect the composition of the workforce through both the changed cost for the employer and the different wages for the prospect employees. Through changes in hiring and applying by future employees the changes might cause sorting and change the composition of the workforce, which can in turn affect the productivity of the workers.

We furthermore analyze a number of heterogeneous effects. First, the consequences of the wage system changes are different among ages, hence incentives are different. From Table 1 we see that the increase in fixed pay is larger for older workers. Compared to younger workers they can therefore achieve the same utility in the new system with relatively less effort. Consequently we expect that the drop in average scores is larger for older workers in the new wage structure. Second, agency 
theory predicts that high-ability workers will suffer more from the change in the pay structure than low-ability workers (Lazear 2000; Franceschelli et al. 2010). The fixed pay component binds for especially low-ability workers, hence they will respond less to the changed incentive scheme than high-ability workers. In our data the position of the worker (captain, promoter or talent) is closely related to ability with captains being the high-ability workers. Third, we investigate whether the average response to changed incentives is constant over time. Gneezy and List (2006) note that there are behavioral differences between psychological processes in the short run and in the long run. In two field experiments they test the dynamics of worker effort over time and find that a gift or higher wages only temporarily increases worker effort. In our empirical analysis we will therefore allow and test for time-varying productivity effects.

\section{Average Effects}

The data supplied by the Dutch marketing company contain information on individual workers and shifts from the beginning of 2013 through October 2014. The data can be viewed as panel data with individual employees performing shifts in multiple periods. For the statistical analysis of the pay structure change introduced on 1 January 2014, we use the balanced sample period 1 July 2013 - 30 June 2014. This sample contains 28,993 shifts worked in 2013 (July-December) and 27,112 shifts in 2014 (January-June).

Although the data can be viewed as panel data, spacing is highly irregular. Some individuals have shifts every week, while others work a couple of shifts in a year only. The total number of workers active in the sample period 1 July 2013 - 30 June 2014 is 2,867. The minimum and maximum number of days worked is 1 and 227 respectively, while the average number of days worked is around 19.34.

Further descriptive statistics on important variables are shown in Table 3. We distinguish two periods, i.e. the old regime of 2013 and the new regime starting in January 2014.

The productivity measure used in this analysis is the score of a single worker in one shift of five hours. The score is simply the sales count, e.g. the number of new newspaper subscriptions or charity donators. This is the measure which the company uses to evaluate its employees and is the basis for the performance based pay. The average score achieved in July-December 2013 was 3.97 units sold with a standard deviation (sd) of 8.37. In the period January-June 2014 an average score of only 2.94 (sd is 3.23) results. These simple statistics suggest that switching from performance related pay (piece rates and bonuses) to hourly wages leads to lower output and less variation corroborating the theoretical and empirical results of Lazear (2000).

The reported empirical quantiles in Table 3 suggest that the changed pay structure was not relevant for all workers as only the top $25 \%$ of the score distribution has been affected. The incentive for performance, however, is the important part of the compensation curve. To achieve high sales scores, employees must perform well throughout their shift. The payout for high sales targets are thus relevant for all observed shifts, even if the targets are not reached. Furthermore, after four shifts the 
Table 3 Descriptive statistics

\begin{tabular}{lll}
\hline regime & old & new \\
\hline total number of shifts & 28,993 & 27,112 \\
number of shifts by Captains & 7,516 & 7,460 \\
number of shifts by Promoters & 16,993 & 15,863 \\
number of shifts by Talents & 4,482 & 3,789 \\
total number of Projects & 128 & 137 \\
average (sd) score & $3.97(8.37)$ & $2.94(3.23)$ \\
average age & $20.27(2.32)$ & $20.62(2.26)$ \\
percentage female & 38.65 & 38.85 \\
percentage male & 61.35 & 61.15 \\
& & \\
percentiles score distribution & & 0 \\
5 & 0 & 0 \\
10 & 0 & 2 \\
25 & 1 & 4 \\
50 & 2 & 6 \\
75 & 4 & 0 \\
95 & 8 &
\end{tabular}

Based on 56,103 observations; numbers between parentheses are standard deviations. Old and new refer to old (2013) and new (2014) wage structure regimes

captains decide if a talent gets promoted to promoter based on the scores of those shifts. As a promoter, consistent performance is expected. Depending on the project, this will consist of a score that is at least as high as the first team bonus. Captains and the area management can decide to terminate contracts in case of underperformance. All this together makes the upper part of the payment structure relevant for all workers.

\section{Baseline Estimate}

The simple statistics in Table 3 do not take into account other relevant factors. In our regression analysis below we distinguish individual workers' attributes, organization specific factors and external influences. Observed worker attributes are position (talent, promoter, captain), tenure (number of shifts worked) and age (years) of the worker. Due to the age-specific implications of the new pay structure, age is included by a number of age-specific dummy variables and not linearly..$^{5}$ Organization specific factors are location and projects. As the company lets its employees work on

\footnotetext{
${ }^{5}$ We distinguish the age categories $<19,19,20,21,22$ and $>22$ years.
} 
different projects over time, with different characteristics and results for each project, the project fixed effects are an important addition to the individual control variables. The company has conducted in the data's timespan in total 195 different projects. Finally, sales teams mainly operate outdoors and therefore scores will depend on weather conditions, which can influence the amount and willingness to buy. We use daily temperature and rainfall data from the Royal Netherlands Meteorological Institute $^{6}$ to control for these external influences.

We estimate a variety of linear regression specifications. A typical regression has the following form:

$$
y_{i t}=\beta_{0}+\beta_{1} d_{t}+\gamma^{\prime} w_{i t}+\varepsilon_{i t},
$$

where $y_{i t}$ is the score of an individual worker $i$ in a particular shift on day $t$. In other words, the data are classified as daily panel data at the worker level. ${ }^{7}$ A distinctive feature is that the panel data are unbalanced and irregularly spaced, i.e. employees do not work all days. For each worker $i$ we have $n_{i}$ observations (with $1 \leq n_{i} \leq 227$ ) and we observe data at times $t_{i, j}$ for $j=1, \ldots, n_{i}$.

The dummy variable $d_{t}$ indicates the different compensation systems ( 0 for observations in 2013 and 1 in 2014). The coefficient $\beta_{1}$ is the parameter of interest as it measures the average difference in scores due to the change in the performance pay system. The vector $w_{i t}$ contains control variables (worker attributes, organization factors and external influences) and $\varepsilon_{i t}$ is an error term.

The novel feature of the research design is the move away from performance pay to more fixed pay. It was an exogenous shift in the sense that the reason for the change was not related to productivity. All linear specifications are estimated by Ordinary Least Squares (OLS). As employees work in teams, performances of individual workers within the same teams might be correlated. To account for this and other exogenous daily factors, we therefore supplement coefficient estimates with clustered standard errors where clusters are chosen to depend on the date of a shift.

The simultaneous changes in the fixed pay structure and bonus scheme make it impossible to distinguish between their separate effects on productivity. Our main focus in the empirical analysis therefore is on estimating the combined effect. Because all workers were subject to the change in pay structure, i.e. we have observational rather than experimental data, our baseline specification (1) is essentially a before-after analysis.

Since all workers were affected, i.e. there is no proper control group, the change in pay structure is likely to be confounded with other developments both within and outside the firm. Regarding internal factors, in the sample period there were no other reorganizations within the firm apart from the change in pay structure. External factors, however, may well have changed from 2013 to 2014. If this is the case, their effects are likely to show up in the dummy variable measuring the different

\footnotetext{
${ }^{6}$ We used the data from their weather report station 'Schiphol airport'.

${ }^{7}$ An individual rarely works multiple shifts per day, hence only a few observations concern a different shift at the same day.
} 
Table 4 Explaining individual worker shift scores

\begin{tabular}{|c|c|c|c|c|c|c|}
\hline & (1) & (2) & (3) & (4) & $(5)$ & (6) \\
\hline \multirow[t]{2}{*}{2014} & -1.037 & -1.067 & -0.323 & -0.176 & -0.223 & -0.304 \\
\hline & $(0.122)$ & $(0.149)$ & $(0.069)$ & $(0.060)$ & $(0.052)$ & $(0.080)$ \\
\hline \multirow[t]{2}{*}{ promoter } & & -1.175 & -0.889 & -0.751 & -0.837 & -0.137 \\
\hline & & $(0.051)$ & $(0.050)$ & $(0.046)$ & $(0.034)$ & $(0.045)$ \\
\hline \multirow[t]{2}{*}{ talent } & & -1.233 & -1.054 & -0.845 & -1.306 & -0.029 \\
\hline & & $(0.234)$ & $(0.115)$ & $(0.095)$ & $(0.056)$ & $(0.073)$ \\
\hline \multirow[t]{2}{*}{ tenure } & & -0.003 & 0.002 & 0.003 & 0.003 & 0.001 \\
\hline & & $(0.000)$ & $(0.000)$ & $(0.000)$ & $(0.000)$ & $(0.001)$ \\
\hline \multirow[t]{2}{*}{ rainfall } & & -0.016 & -0.021 & -0.023 & -0.019 & -0.020 \\
\hline & & $(0.012)$ & $(0.010)$ & $(0.009)$ & $(0.006)$ & $(0.006)$ \\
\hline \multirow[t]{2}{*}{ temperature } & & 0.003 & 0.026 & 0.013 & 0.018 & 0.024 \\
\hline & & $(0.015)$ & $(0.010)$ & $(0.009)$ & $(0.005)$ & $(0.005)$ \\
\hline age effects (6) & no & yes & yes & yes & yes & yes \\
\hline location effects (16) & no & no & yes & yes & yes & yes \\
\hline project category effects (35) & no & no & no & yes & no & no \\
\hline project effects (195) & no & no & no & no & yes & yes \\
\hline worker effects $(2,867)$ & no & no & no & no & no & yes \\
\hline $\mathrm{R}^{2}$ & 0.006 & 0.013 & 0.314 & 0.462 & 0.747 & 0.805 \\
\hline
\end{tabular}

Number of observations is 56,103. Clustered standard errors are between parentheses

The regressor '2014' is the dummy variable for the new wage regime in 2014

compensation structures. We therefore include control variables to take into account changes in weather and other external conditions. ${ }^{8}$

Table 4 reports estimation results for various choices of the set of control variables. Column (1) is a simple difference in means analysis without any controls showing that the regime change in incentive pay has had a significant impact on performance. Adding worker attributes (position, age, tenure) and weather conditions (temperature in degrees Celsius, rainfall in $\mathrm{mm}$ ) as control variables results in a similarly large significant effect of the change in wage system as can be seen from column (2). The explanatory power is still low, however, as differences between projects and locations are ignored by this specification. Including dummy variables for the company's office locations and 35 project categories produces a smaller, but still significant negative coefficient as can be seen from columns (3) and (4).

Because the wage system and projects are correlated, since some of the projects ran through only one system and some through both, including variables related to

\footnotetext{
${ }^{8}$ To capture economic conditions we also experimented with monthly macroeconomic control variables like the unemployment rate and inflation rate. The explanatory power of such aggregated indicators was very low, however.
} 
the projects will most likely absorb some of the effect of the wage system change. This is confirmed by regressing score on the individual variables, weather indicators, location dummies and furthermore 195 project fixed effects. The results of this regression are in column (5) of Table 4. Adding the project fixed effects leads to a large increase of the $R^{2}$ from 0.462 to 0.747 showing their relevance for explaining the cross-sectional variation in shift scores.

To further control for unobserved heterogeneity among individual workers, we include fixed effects for every single worker. In other words, we decompose the error term in specification (1) as $\varepsilon_{i t}=\alpha_{i}+u_{i t}$ with $\alpha_{i}$ a worker fixed effect. Adding 2,867 worker specific dummies to the model and exploiting the within estimator results in column (6) of Table 4 . There is only a modest increase of $R^{2}$ due to the inclusion of the worker fixed effects. Note that the coefficients of other worker attributes like age and position are still identified as these control variables do vary over time. By including worker fixed effects their interpretation has changed, however. Without worker effects the coefficients of age and position mainly reflect time invariant differences between workers (e.g. ability). This between worker variation is substantially larger than the variation over time for an individual worker. The corresponding coefficients therefore change substantially in the specification with worker fixed effects.

The effect of the regime change remains large and significant in the specification with worker fixed effects. The switch from the old to new system reduces sales by 0.304 unit sold per shift. The average score in 2013 is 3.97, which implies a reduction in sales of around $7.65 \%$.

\section{Sorting}

The large and significant effects of the compensation system changes are clear in all regressions presented. There are two possible interpretations of this effect. First the pure incentive effect of the regime change on extrinsic motivation, causing a decrease in effort and subsequently score. Second the effect might be due to sorting, as the workforce might have changed in composition due to the different compensation system.

To see the effects of the system changes on workforce composition, a quick look at average ages shows an increase in average age of 0.35 years (see Table 3 ). This increase in the number of older workers can be explained by the differentiation in wage structure across ages. ${ }^{9}$ Higher ages earn more fixed pay than lower ages in the newer compensation systems. The increased average age can have both a negative and positive effect on output. Since age is significant across all regressions and higher ages indicate higher scores, one might expect average scores to increase with an increase in the average age of the employees. In this case the opposite might be true. As higher aged employees now earn the same wages for lower score levels, lower ability individuals might now be able to earn satisfactory wages and apply. This causes the ability of the average worker to decline and thus reducing score levels.

\footnotetext{
${ }^{9}$ Note that the simple passage of time in a balanced panel produces the same age effect.
} 
In our empirical analysis we distinguished between incentive and sorting effects by exploiting the longitudinal nature of the data. To control for the unobserved ability of individual workers, we included fixed effects for every single worker in column (6) of Table 4. The coefficient estimate of the regime switch dummy can therefore be interpreted as a pure incentive effect, i.e. controlling for unobserved worker ability.

To further control for sorting we re-estimate the model including worker fixed effects, but only using data from individuals who have been working for the company in both compensation systems. We thus drop new workers and only analyze the development of productivity of workers who have been active before and after the pay structure change. The coefficient estimate (standard error) is $-0.226(0.087)$, which is somewhat smaller than the corresponding estimate in column (6) of Table 4.

Finally, we compare the productivity of new and old workers using only the 2014 data. We introduce a dummy indicator, which is one for individuals who started working in 2014. The estimated coefficient is -0.002 and insignificant (standard error is 0.042). This implies that ability of new and old workers is not different, hence sorting effects are largely absent.

\section{Sensitivity Analysis}

We consider a number of alternative specifications to our baseline regressions as reported in the last two columns of Table 4. The results of these various robustness checks are reported in Table 5. We report estimates without and with worker fixed effects and compare them with the corresponding baseline estimates in columns (5) and (6) of Table 4 respectively.

To further control for unobserved heterogeneity over time, we include fixed effects for every calendar week. As calendar week 1 of the year 2014 started December 30, 2013, there is no perfect multicollinearity between the calendar week fixed effects and the dummy variable $d_{t}$ in (1) measuring the change in the compensation system on January 1, 2014. Row (2) of Table 5 reports estimation results adding 52 week dummies. The coefficient is more negative compared to the specification without week dummies indicating an even larger productivity effect.

The dependent variable, i.e. shift score, has so far been used as a continuous variable in a linear regression analysis. The results of such linear regressions produce

Table 5 Sensitivity analysis

\begin{tabular}{lcr}
\hline & no worker effects & worker effects \\
\hline (1) baseline results & $-0.223(0.052)$ & $-0.304(0.080)$ \\
(2) including week effects & $-0.422(0.088)$ & $-0.366(0.093)$ \\
(3) Poisson regression & $-0.079(0.017)$ & $-0.114(0.026)$ \\
(4) january-june data only & $-0.288(0.042)$ & $-0.227(0.054)$ \\
\hline
\end{tabular}

Worker attributes, weather conditions, location and project effects included as control variables. Clustered standard errors are reported between parentheses 
significant results and offer easier interpretation in the sense that the coefficients are marginal effects. The actual format of the scores, however, is a count. Maximum Likelihood estimation results using the Poisson count model are reported in row (3). The results of these count data regressions are in line with the results found in the linear specifications. Both regressions show a significant negative impact of the system change. The implied marginal effects equals -0.27 and -0.40 in the Poisson models without and with worker fixed effects respectively.

Finally, Row (4) reports estimation results of the linear specification again, but using only January-June data for both 2013 and 2014. In other words, it compares the period in which the new system was used in 2014 with exactly the same period in 2013. The estimates are significant and of similar magnitude as the baseline results in row (1).

\section{Heterogeneous Effects}

Our baseline estimate of the decrease in shift scores can be interpreted as an average effect of the wage regime change. As outlined before, however, the change in pay structure had different consequences for different workers. Young and/or highability workers were more adversely affected than old and/or low-ability workers. We therefore analyze the heterogeneity in response across age and position. We extend our baseline specification with interaction terms of the regime dummy $d_{t}$ with either age or position categories. Furthermore, we analyze time-varying responses to investigate in more detail how workers adapted over time to the new incentive scheme. Finally, we analyze the impact of a second change in the pay structure in July 2014, which only affected the captains. For all cases we report estimates without and with worker fixed effects and compare them with the corresponding baseline estimates in columns (5) and (6) of Table 4 respectively.

\section{Age}

As discussed in "Research Design", the consequences of the wage system changes are different among ages. We therefore interact the compensation system dummy with the 6 age-specific dummy regressors ranging from $<19$ to $>22$ years. The regression results in the first row of Table 6 , i.e. without worker fixed effects, are

Table 6 Age-specific interactive effects

\begin{tabular}{lllllllll}
\hline worker effects & baseline & $>22$ & 22 & 21 & 20 & 19 & $<19$ & $\mathrm{R}^{2}$ \\
\hline no & -0.223 & -0.385 & -0.419 & -0.319 & -0.124 & 0.080 & -0.291 & 0.748 \\
& $(0.052)$ & $(0.087)$ & $(0.099)$ & $(0.075)$ & $(0.080)$ & $(0.077)$ & $(0.074)$ & \\
yes & -0.304 & -0.362 & -0.440 & -0.122 & -0.324 & -0.103 & -0.460 & 0.805 \\
& $(0.080)$ & $(0.125)$ & $(0.141)$ & $(0.105)$ & $(0.114)$ & $(0.102)$ & $(0.110)$ & \\
\hline
\end{tabular}

See Table 5. Columns headings indicate age categories in years 
Table 7 Position-specific interactive effects

\begin{tabular}{llllll}
\hline worker effects & baseline & captains & promoters & talents & $\mathrm{R}^{2}$ \\
\hline no & -0.223 & -0.533 & -0.133 & -0.026 & 0.748 \\
& $(0.052)$ & $(0.070)$ & $(0.058)$ & $(0.097)$ & \\
yes & -0.304 & -0.427 & -0.228 & -0.320 & 0.805 \\
& $(0.080)$ & $(0.090)$ & $(0.084)$ & $(0.124)$ & \\
\hline
\end{tabular}

See Table 5

in line with the expectations formed in the compensation system analysis. As higher age groups earn more fixed pay and have the option to achieve the same utility with much less effort, one expects the effect on performance to be larger for the higher ages. The effects become smaller down to age 19, then rise a little bit for the lowest ages. This might be explained by the fact that from ages 18 and younger, the employees in the new compensation system earn both less fixed pay and less performance based salary, resulting in a much lower monetary incentive for any score.

This pattern of heterogeneous effects, depending on age, becomes somewhat less clear when we add worker specific fixed effects as shown in the second row of Table 6. Workers aged 21 do not significantly show less shift scores, while the opposite holds for 20 year old workers. ${ }^{10}$ Nevertheless, the negative impact of the change in the wage system is observed again for all age categories.

\section{Position}

We also analyze the consequences of the wage system changes for different positions. From our baseline estimates without worker specific effects in column (5) of Table 4 we see that position reflects the ability distribution, i.e. promoters have lower scores than captains and talents have lower scores than promoters. We therefore interact the compensation system dummy with the 3 position-specific dummy regressors, i.e. captains, promoters and talents.

Regarding the model without worker specific effects, the regression results for different position-specific interaction terms are in line with the expectations formed in the compensation system analysis. The difference in variable pay was largest for captains and indeed these workers experience the largest drop in productivity as can be seen from Table 7. Talents are relatively insensitive to the performance pay system, which can partly explained by the fact that their variability in scores is large. When we include worker specific effects to control for worker ability, we find similar results for captains and promoter, but now we find a significant negative effect for talents too.

\footnotetext{
${ }^{10}$ We conjecture that the different interpretation of age and position coefficients in the specification with worker fixed effects, as discussed before, partly explains this changed pattern in the estimation results.
} 
Table 8 Time-varying effects

\begin{tabular}{lccccc}
\hline worker effects & baseline & 1-14 Jan & 15-31 Jan & 1 Feb-31 Mar & 1 Apr-30 Jun \\
\hline no & -0.223 & -0.548 & -0.303 & -0.172 & -0.135 \\
& $(0.052)$ & $(0.098)$ & $(0.145)$ & $(0.065)$ & $(0.062)$ \\
yes & -0.304 & -0.555 & -0.314 & -0.228 & 0.100 \\
& $(0.080)$ & $(0.090)$ & $(0.188)$ & $(0.097)$ & $(0.104)$ \\
$\mathrm{N}$ & 56,103 & 30,755 & 31,496 & 37,890 & 43,223 \\
\hline
\end{tabular}

See Table 5

\section{Time}

We analyze whether the estimated productivity effect is persistent over time. We therefore estimate the baseline specifications using different samples after the wage change. We distinguish four different 2014 samples, i.e. January 1 - January 14, January 15 - January 31, February 1 - March 31 and April 1 - June 30. The estimation results are in Table 8.

The pattern of estimates without worker specific effects strongly suggest that the short-run response to the new wage regime is stronger than the long-run response. In the first two weeks the average decrease in score is 0.55 units, while it is only 0.14 units after 3 months. These results suggest that the short-run response has been more negative than the long-run response. For the model including worker specific effects we find similar results.

The quick decay of the incentive effect is likely due to the fact that for incumbent workers the decrease in monetary incentive was only felt temporary. The upper part of the payment profile likely became relevant again just as it was before the payment structure change. Furthermore, there has been a high rate of employee turnover. Of employees working in June 2014, about $50 \%$ has been hired in the new compensation regime in 2014. These workers have not felt the decrease in monetary incentive as a result of the change in payment at all.

\section{Second Change}

The company implemented a second change in its compensation structure in July 2014. As the management of the company became aware of the drop in incentive that the new system had caused, they decided to change the structure for captains. The captains once again received individual bonuses and their fixed wage was reduced to the level of promoters and talents.

Figure 3 represents the new situation for captains. The linear trend approximating performance related pay in the newest system is slightly smaller than it was in the old system (with a coefficient of 14.57 in the newest versus 15.39 in the old system). We therefore conclude that for captains working in the newest wage system the monetary incentive to perform is higher than in the January till June 2014 system and brings it back to almost the level of the old system in 2013 . 

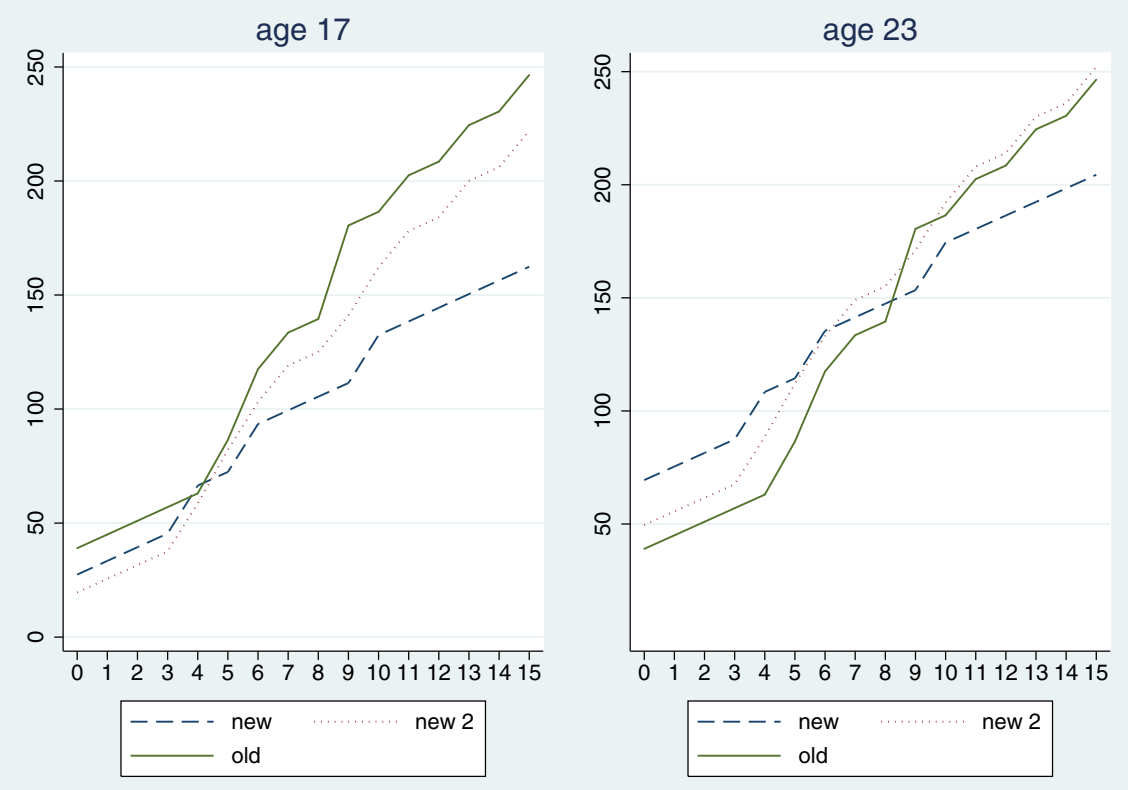

Fig. 3 Second compensation structure change for Captains. See Fig. 1. "new 2" refers to second change implemented in July 2014

For the statistical analysis of this second pay structure change we use the balanced sample period 15 March 2014 - 15 October 2014. The set of control variables is the same as before and we again report results with and without worker specific effects. From Table 9 it is seen that, in the specifications without worker specific effects, this second change in wage structure has had a positive effect on the performance of captains. The before-after comparison (row 1) shows that captains on average achieve a 0.204 higher score in shifts after 1 July 2014. Furthermore, average scores for promoters and talents do not change significantly (rows 2 and 3 ).

Table 9 Second change for captains

change in mean score:
(1) captains
(2) promoters
(3) talents

DiD control group:
(4) promoters
(5) talents
(6) both

no worker effects

$$
\begin{aligned}
& 0.204(0.109) \\
& 0.042(0.067) \\
& -0.089(0.116)
\end{aligned}
$$

$$
\begin{aligned}
& 0.243(0.072) \\
& 0.254(0.098) \\
& 0.253(0.070)
\end{aligned}
$$

worker effects

$-0.063(0.142)$

$-0.136(0.082)$

$-0.156(0.201)$

0.109 (0.076)

$-0.336(0.169)$

$0.081(0.075)$

See Table 5 
Because the wage structure for promoters and talents was not affected, they can serve as control group in Differences-in-Differences (DiD) estimation. Rows 4 and 5 of Table 9 show the DiD estimates using promoters and talents respectively as separate control groups, while row 6 combines both control groups. The three DiD estimates clearly show a positive and significant productivity effect for captains. Furthermore, average scores for promoters and talents do not change at all, which gives confidence in the validity of these control groups. It also shows the absence of spillover effects from captains to promoters/talents, however.

When we add worker specific effects to the DiD analysis, however, estimation results are often not significant as can be seen from column 2 of Table 9. A further remarkable result is that using only talents as control group, the DiD estimate is negative.

\section{Concluding Remarks}

We have analyzed empirically the relation between monetary compensation and performance. The effects of changes in the compensation method have been estimated using worker level data from a large field marketing company based in the Netherlands. The company has implemented a new pay structure with a higher fixed pay and lower bonuses as of January 2014. Contrary to many other empirical studies, we therefore analyze the impact on worker productivity of a reduction in performance pay.

Using data from 2013 and 2014, i.e. before and after the intervention, our estimated regression specifications indicate a significant reduction in individual shift scores due to the lower monetary incentive to perform. Although the details of the compensation system and the changes for different positions and ages are quite intricate, the results for all combinations of worker positions and ages are significant. On average the changes in the pay structure have caused a more than $7 \%$ reduction in actual sales. Since fixed pay and bonuses have been changed simultaneously, we interpret this estimate as the joint average effect of higher fixed pay and lower bonuses on productivity.

The empirical results corroborate with the primary prediction of agency theory. Average effort has at least not increased in the new compensation system. The sharp drop in performance found, even when controlling for a host of relevant determinants including location and project fixed effects, shows that employees have most likely decreased their effort resulting in lower sales performance. We have exploited the longitudinal dimension of the data to distinguish between incentive and sorting effects. Controlling for ability by including worker specific effects we find pure incentive effects, while sorting is largely absent.

We furthermore have analyzed heterogeneity in the incentive effects by estimating age and position specific regressions. We find that older workers experienced the largest drop in productivity corroborating with the fact that changes in the wage structure were largest for those workers. Also we find that high-ability workers, i.e. captains, experience a larger drop in productivity corroborating agency theory. Finally, allowing for time-varying effects we find that the productivity drop is largest in the first weeks after the change in pay structure. 
We also analyzed a second change in the pay structure. As the management of the company became aware of the drop in incentive that the new system had caused, they decided to change the pay structure for captains again in July 2014. Because the wage structure for promoters and talents was not affected, we use them as control group in differences-in-differences estimation. Although not entirely robust, the empirical results show an increase of individual shift scores for captains due to the higher monetary incentive to perform.

Our analysis can be viewed as a case study and adds to the empirical literature on the effectiveness of performance pay systems using personnel data of a single firm. The composition of the workforce at the company under investigation is quite specific, with a narrow age range and mostly part-timers (students). Nevertheless, there are a number of comparable sectors for which our results might be especially relevant. Examples are the hospitality industry, marketing companies, supermarkets, the retail industry and sales companies. Additionally, the results of this analysis have to be taken into account by policy makers, when wage legislation like minimum wages are considered. The discussion on minimum wages focuses mainly on the end wage of the workers and not on its structure. The effect of this structure on the performance of workers, like demonstrated in this analysis, can cause a double dip effect for companies required to pay a minimum wage if this wage reduces the workers' performance-pay incentives.

Funding Information The research of M.J.G. Bun has been funded by the NWO Vernieuwingsimpuls research grant nr. 016.115.320.

\section{Compliance with Ethical Standards}

Conflict of interests The authors declare that they have no conflict of interest.

Open Access This article is distributed under the terms of the Creative Commons Attribution 4.0 International License (http://creativecommons.org/licenses/by/4.0/), which permits unrestricted use, distribution, and reproduction in any medium, provided you give appropriate credit to the original author(s) and the source, provide a link to the Creative Commons license, and indicate if changes were made.

\section{References}

Bandiera O, Barankay I, Rasul I (2005) Social preferences and the response to incentives: evidence from personnel data. Q J Econ 120(3):917-962

Forth J, Bryson A, Stokes L (2014) Are firms paying more for performance? NIESR Discussion Paper No. 423, London

Franceschelli I, Galiani S, Gulmez E (2010) Performance pay and productivity of low- and high-ability workers. Labour Econ 17:317-322

Gielen AC, Kerkhofs MJ, Van Ours JC (2010) How performance related pay affects productivity and employment. J Popul Econ 23(1):291-301

Gittleman M, Pierce B (2013) How prevalent is performance-related pay in the United States? Current incidence and recent trends. Natl Inst Econ Rev 226:R4-R16

Gneezy U, List JA (2006) Putting behavioral economics to work: Testing for gift exchange in labor markets using field experiments. Econometrica 74(5):1365-1384 
Jones DC, Kalmi P, Kauhanen A (2006) Human resource management policies and productivity: new evidence from an econometric case study. Oxf Rev Econ Policy 22(4):526-538

Jones DC, Kalmi P, Kauhanen A (2010) Teams, incentive pay, and productive efficiency: evidence from a food-processing plant. Ind Labor Relat Rev 63(4):606-626

Kishore S, Rao RS, Narasimhan O, John G (2013) Bonuses versus commissions: a field study. J Mark Res 50(3):317-333

Lazear EP (1986) Salaries and piece rates. J Bus 59(3):405-431

Lazear EP (2000) Performance pay and productivity. Am Econ Rev 90(5):1346-1361

Origo F (2009) Flexible pay, firm performance and the role of unions. New evidence from Italy. Labour Econ 16:64-78

Prendergast C (1999) The provision of incentives in firms. J Econ Lit 37(1):7-63

Van Herpen M, Van Praag M, Cools K (2005) The effects of performance measurement and compensation on motivation: an empirical study. The Economist 153(3):303-329

Young GJ, Beckman H, Baker E (2012) Financial incentives, professional values and performance: a study of pay-for-performance in a professional organization. J Organ Behav 33(7):964-983 